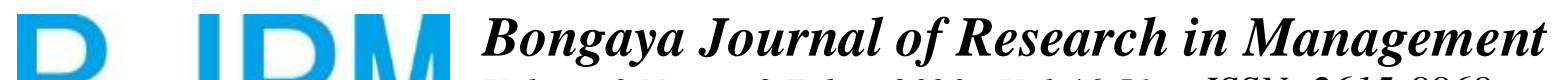 Volume 3 Nomor 2 Tahun 2020.. Hal 46-51. e-ISSN: 2615-8868
}

Homepage: https://ojs.stiem-bongaya.ac.id/index.php/BJRM

\section{ANALISIS KUALITAS PRODUK, PROMOSI DAN LAYANAN TERHADAP KEPUTUSAN PEMBELIAN}

\section{ANALYSIS OF PRODUCT QUALITY, PROMOTION AND SERVICE TO PURCHASE DECISIONS}

\author{
Anggraeni Nurhidayati \\ Universitas Islam Batik Surakarta, Indonesia \\ Email: nurhidayatanggraini@gmail.com,
}

(Diterima: 19 September 2020; direvisi: 15 Oktober 2020; dipublikasikan: 07 Desember 2020 )

(7) (8) C2018 -Bongaya Journal for Research in Management STIEM Bongaya. Ini adalah artikel dengan akses terbuka dibawah licenci CC BY-NC-4.0 (https://creativecommons.org/licenses/by-nc/4.0/ ).

\begin{abstract}
This study aims to determine the analysis of the influence of product quality, promotion and service on purchasing decisions. This research was conducted at the Fast Food Restaurant Wendys in the Solobaru area. The population in this study were all consumers of Wendy's fast food restaurants. The sample used was Wendy's Solobaru consumers during the research period April 2018 amounting to 310 and with. The technique used in sampling is accident sampling technique. This study was analyzed using quantitative research methods. The results of the study showed that: The effect of product quality on has a positive and significant effect on purchasing decisions. Promotion has positive and significant influence on purchasing decisions. The effect of service on customer loyalty has a positive and significant effect on purchasing decisions.
\end{abstract}

Keywords: Product Quality; Promotion ; Service

\begin{abstract}
Abstrak : Penelitian ini bertujuan untuk mengetahui analisis pengaruh kualitas produk, promosi dan layanan terhadap keputusan pembelian. Penelitian ini dilakukan di Restoran Fast Food Wendy's daerah Solobaru. Populasi dalam penelitian ini adalah semua konsumen restoran fast food wendy's. Sampel yang digunakan adalah konsumen Wendys Solobaru selama periode penelitian April 2018 berjumlah 310 dan dengan. Teknik yang digunakan dalam pengambilan sampel adalah teknik accidental sampling. Penelitian ini dianalisis menggunakan metode penelitian kuantitatif .Hasil dari penelitian menunjukan bahwa: Pengaruh kualitas produk terhadap memiliki pengaruh positif dan signifikan terhadap keputusan pembelian. Pengaruh promosi pengaruh positif dan signifikan terhadap keputusan pembelian. Pengaruh pelayanan terhadap loyalitas pelanggan memiliki pengaruh positif dan signifikan terhadap keputusan pembelian .
\end{abstract}

Kata kunci: Kualitas Produk; Promosi; Pelayanan 


\section{PENDAHULUAN}

Setiap orang pasti mempunyai banyak pertimbangan tentang sesuatu sebelum melakukan keputusan pembelian. Di jaman modern ini bisnis dibidang kuliner mempunyai kecenderungan terus meningkat, semua manusia pasti membutuhkan makanan untuk melangsungkan hidupnya, begitu juga dalam menentukan keputusan memilih tempat kuliner yang semakin banyak. Para penjual dapat memahami konsumen dengan baik melalui pengalaman menjual produk secara langsung kepada mereka.

Perlunya peningkatan variasi rasa ataupun kandungan gizi yang ada sehingga konsumen semakin banyak pilihan. Maka produk dapat bersaing di pasaran, sehingga menjadikan konsumen memiliki banyak alternatif ragam produk sebelum mengambil keputusan untuk membeli suatu produk yang ditawarkan. Berdasarkan pemantauan yang dilakukan terhadap beberapa hal yang mempengaruhi keputusan konsumen dalam membeli produk makanan di restaurant fast food Wendy's Solo Baru, diantaranya yaitu konsumen melihat apakah produk tersebut berkualitas dan baik untuk dikonsumsi karena banyaknya restaurant yang menggunakan bahan-bahan kimia yang berbahaya bagi tubuh. Kenyataannya restoran fast food Wendy's sangat terjaga kualitasnya, banyak varian menu, aman untuk dikonsumsi karena sistem pemasakannya make to order langsung dibuat ketika ada pesanan atau pembelian.

Rumusan masalah dalam penelitian ini yaitu (1) Apakah ada pengaruh secara simultan kualitas produk, promosi dan pelayanan terhadap keputusan pembelian konsumen Fast Food Wendy's Solobaru ? (2)Apakah ada pengaruh kualitas produk terhadap keputusan pembelian konsumen Fast Food Wendys Solobaru ? (3) Apakah ada pengaruh promosi terhadap keputusan pembelian konsumen Fast Food Wendy's Solobaru? (4) Apakah ada pengaruh pelayanan terhadap keputusan pembelian konsumen Fast Food Wendys Solobaru?

\section{Keputusan Pembelian}

Dalam memahami perilaku konsumen terhadap banyak pengaruh yang mendasari seseorang dalam mengambil keputusan pembelian suatu produk dan tempat kuliner.
Rangsangan tersebut kemudian didesain sesuai karakteristik dalam diri konsumen untuk menentukan keputusan dalam memilih tempat kuliner. Keputusan pembelian adalah keputusan pembeli tentang merek mana yang dibeli (Kotler dan Amstrong, 2012). Pengambilan keputusan merupakan suatu kegiatan individu yang secara langsung terlibat dalam mendapatkan mempergunakan barang yang ditawarkan.

Menurut Hermawan Kartawijaya (dalam Tafsir at al,2018) ada teori keputusan konsumen ini mempelajari bagaimana individu, kelompok dan organisasi dalam membeli, memilih, memakai dan membuang barang atau jasa dalam rangka memuaskan kebutuhan dan hasrat mereka . Berkowitz (Irawan 2012) mengemukakan bahwa keputusan pembelian merupakan tahap-tahap yang dilalui pembelian dalam menentukan pilihan tentang produk dan jasa yang hendak dibeli. Keputusan pembelian adalah keputusan meneruskan atau tidak meneruskan pembelian.

\section{Kualitas Produk}

Salah satu keunggulan dalam menjalankan bisnis adalah kualitas produk yang dapat memenuhi keinginan konsumen (Kotler \& Keller, 2012). Bila tidak sesuai dengan kriteria maka produk akan ditolak, meskipun produk tersebut masih dalam batas toleransi yang telah ditentukan. Untuk itu sebaiknya perlu diperhatikan agar terhindar dari kesalahan yang lebih besar diwaktu yang akan datang. Demikian pula konsumen dalam membeli suatu produk selalu berharap agar dapat memenuhi kebutuhannya dan sesuai dengan yang diinginkan (Agustin, 2017). Untuk itu perusahaan harus dapat memahami keinginan konsumen sehingga dapat menghasilkan produk yang sesuai dengan harapan konsumen. Kualitas produk merupakan suatu hal yang harus dicover oleh perusahaan karena kualitas produk yang baik merupakan kunci dari perkembangan produktivitas perusahaan. Menurut Kotler dan Amstrong (2012) produk adalah "A product is anything that can be offered to a market to satisfy a want or need". Artinya, produk adalah segala sesuatu yang ditawarkan ke pasar untuk memuaskan sebuah keinginan atau kebutuhan. Paulus Lilik Kristianti (2012: 236) menyatakan produk suatu sifat yang kompleks, baik dapat diraba maupun tidak dapat diraba, termasuk bungkus, warna, harga, prestise perusahaan dan pengecer. Dari definisi diatas dapat disimpulkan 
bahwa produk merupakan segala sesuatu yang diciptakan perusahaan agar dapat ditawarkan untuk mendapatkan perhatian dalam memuaskan keinginan dan kebutuhan konsumen.

\section{Promosi}

Promosi merupakan salah satu variabel dalam bauran pemasaran yang sangat penting untuk dilaksanakan oleh perusahaan dalam memasarkan produk. Kegiatan promosi bukan saja berfungsi sebagai alat komunikasi antara perusahaan dan konsumen, melainkan juga sebagai alat untuk mempengaruhi konsumen dalam kegiatan pembelian atau penggunaan produk sesuai dengan kebutuhan dan keinginannya (Sunyoto, 2012).

(Musthafa 2012) promosi adalah mengkomunikasikan informasi antara penjual dan pembeli potensial atau orang lain dalam saluran untuk mempengaruhi sikap dan perilaku.

Dari uraian tersebut dapat disimpulkan bahwa promosi merupakan penyampaian informasi dari penjual atau produsen kepada pembeli atau konsumen untuk mempengaruhi sikap dan tingkah laku dalam rangka menciptakan pertukaran, sehingga tujuan untuk meningkatkan kuantitas penjualan diharapkan dapat terealisasi dengan baik.

\section{Pelayanan}

Dalam persaingan yang semakin lama semakin ketat ini, maka pelayanan terhadap pelanggan mempunyai peranan yang sangat penting. Pada dasarnya proses pelayanan konsumen adalah semua kegiatan yang dilakukan untuk memberikan kepuasaan kepada konsumen yang kelak akan berujung kepada keputusan pembelian. Menurut Kotler dan Keller (2012) pelayanan adalah setiap tindakan atau kegiatan yang ditawarkan oleh suatu pihak kepada pihak lain yang pada dasar tidak berwujud dan tidak mengakibatkan kepemilikan apapun. Jadi dapat disimpulkan pelayanan merupakan perilaku produsen dalam rangka memenuhi kebutuhan dan keinginan konsumen demi tercapainya kepuasan pada konsumen itu sendiri (Agustin, 2017)..

Kotler \& Keller (2012) juga mengatakan bahwa perilaku tersebut dapat terjadi pada saat sebelum dan sesudah terjadi transaksi. Pada umumnya yang bertaraf tinggi akan menghasilkan kepuasan yang tinggi serta keputusan pembelian yang banyak.

\section{METODE}

Penelitian ini menganalisis pengaruh antara kualitas produk, promosi dan layanan terhadap keputusan pembelian, berdasarkan kajian teoritis dan empiris dijelaskan bahwa kualitas produk dan promosi serta layanan memiliki korelasi positif terhadap keputusan pembelian. Secara teoritis dijelaskan bahwa kualitas produk yang baik berarti membuat konsumen merasa puas dan akan melakukan pembelian ulang terhadap produk tersebut.

Jenis penelitian yang digunakan adalah kuantitatif. Sumber data dalam penelitian ini adalah data primer, adapun alat pengumpulan data dilakukan dengan teknik angket berdasarkan skala Likert dengan, dengan variabel :

$\begin{array}{ll}\text { X1 } & =\text { Kualitas Produk } \\ \mathrm{X} 2 & =\text { Promosi } \\ \text { Y2 } & =\text { Layanan } \\ \text { Y1 } & =\text { Keputusan Membeli } \\ \alpha 0, \beta 0 & =\text { Konstanta } \\ \alpha 1, \beta 1, \beta 2, \beta 3 & =\text { Koefisien Regresi } \\ \epsilon & =\text { Error Term } \\ \alpha 0, \beta 0 & =\text { Konstanta }\end{array}$

\section{HASIL DAN PEMBAHASAN}

Berikut disajikan karakteristik responden yang meliputi jenis kelamin, usia, dan tingkat pendidikan responden.

Tabel 1. Hasil Uji Validitas Data

\begin{tabular}{|c|c|c|c|c|}
\hline No & $\begin{array}{l}\text { Variabel } \\
\text { /Indikator }\end{array}$ & R Hitung & $\begin{array}{c}\mathbf{R} \\
\text { Tabel }\end{array}$ & Keterangan \\
\hline \multirow[t]{6}{*}{1} & Kualitas & Produk & $\mathrm{X1}$ & \\
\hline & $\mathrm{X} 1.1$ & 0,577 & 0,195 & Valid \\
\hline & $\mathrm{X} 1.2$ & 0,786 & 0,195 & Valid \\
\hline & $\mathrm{X} 1.3$ & 0,772 & 0,195 & Valid \\
\hline & $\mathrm{X} 1.4$ & 0,757 & 0,195 & Valid \\
\hline & $\mathrm{X} 1.5$ & 0,500 & 0,195 & Valid \\
\hline \multirow[t]{6}{*}{2} & Promosi & & $\mathrm{X} 2$ & \\
\hline & $\mathrm{X} 1.1$ & 0,858 & 0,195 & Valid \\
\hline & $\mathrm{X} 1.2$ & 0,851 & 0,195 & Valid \\
\hline & $\mathrm{X} 1.3$ & 0,856 & 0,195 & Valid \\
\hline & $\mathrm{X} 1.4$ & 0,672 & 0,195 & Valid \\
\hline & $\mathrm{X} 1.5$ & 0,802 & 0,195 & Valid \\
\hline \multirow[t]{4}{*}{3} & Layanan & & X3 & \\
\hline & X3.1 & 0,827 & 0,195 & Valid \\
\hline & $\mathrm{X} 3.2$ & 0,882 & 0,195 & Valid \\
\hline & X3.3 & 0,652 & 0,195 & Valid \\
\hline
\end{tabular}




\begin{tabular}{ccccc}
\hline & X3.4 & 0,650 & 0,195 & Valid \\
\hline & X3.5 & 0,839 & 0,195 & Valid \\
\hline 4 & Keputusan & Pembelian & Y1 & \\
\hline & Y2.1 & 0,717 & 0,195 & Valid \\
\hline Y2.2 & 0,601 & 0,195 & Valid \\
\hline Y2.3 & 0,711 & 0,195 & Valid \\
\hline Y2.4 & 0,824 & 0,195 & Valid \\
\hline & Y2.5 & 0,710 & 0,195 & Valid
\end{tabular}

dasar keputusan jika $r_{\text {hitung }}>r_{\text {tabel }}$ (sig. 0,05) maka instrumen atau item-item pertanyaan berkorelasi signifikan terhadap skor total (dinyatakan valid).

Pengujian data selanjutnya pada tabel 2 adalah pengujian data untuk mengukur reliabel suatu data, dimana pada penelitian ini data dapat dikatakan realible, ketika nilai Cronbach's Alpha lebih besar dari 0,60. Inilah yang menjadi dasar

Sumber: Data Primer diolah, Tahun 2018

Tabel 2. Hasil Uji Reliabilitas Data

\begin{tabular}{cccc}
\hline No & Variabel & $\begin{array}{c}\text { Cronbach's } \\
\text { Alpha }\end{array}$ & Keterangan \\
\hline $\mathbf{1}$ & $(\mathrm{X} 1)$ & 0,782 & Reliabel \\
\hline $\mathbf{2}$ & $(\mathrm{X} 2)$ & 0,870 & Reliabel \\
\hline $\mathbf{3}$ & $(\mathrm{Y} 1)$ & 0,834 & Reliabel \\
\hline $\mathbf{4}$ & $(\mathrm{Y} 2)$ & 0,789 & Reliabel \\
\hline
\end{tabular}

Sumber: Data Primer diolah, Tahun 2018

Tabel 3. Hasil Uji Determinasi Model Summary

\begin{tabular}{llrrr}
\hline & & \multicolumn{2}{c}{ R } & \multicolumn{2}{c}{$\begin{array}{c}\text { Stdjusted R Error } \\
\text { of the }\end{array}$} \\
Model & $\mathrm{R}$ & Square & \multicolumn{1}{c}{ Square } & \multicolumn{1}{c}{ Estimate } \\
\hline 1 & $.791^{\mathrm{a}}$ & .626 & .615 & 1.4058 \\
\hline
\end{tabular}

a. Predictors: (Constant), X1, X2, X3

Tabel 4. Uji F

\begin{tabular}{l|l|c|c}
\hline Model & \multicolumn{1}{|c|}{ Df } & f & Sig \\
\hline Regression & 6 & 53.625 & $.000^{\prime}$ \\
Residual & 56 & & \\
Total & 62 & & \\
\hline
\end{tabular}

Tabel $5 \quad$ Koefisien Regresi

\begin{tabular}{|c|c|c|c|}
\hline \multirow[b]{2}{*}{ Model } & Unstandardized & & \\
\hline & $\mathrm{B}$ & $\mathrm{t}$ & Sig \\
\hline Constanta & 6.564 & 5.228 & .236 \\
\hline $\mathrm{X} 1$ & .385 & 2.097 & .045 \\
\hline $\mathrm{X} 2$ & .149 & 2.674 & .012 \\
\hline $\mathrm{X} 3$ & .181 & 2.525 & .017 \\
\hline
\end{tabular}

Data pengujian validitas pada variabel kualitas produk, promosi, layanan dan keputusan pembelian yang didapatkan dari hasil penelitian menunjukkan bahwa seluruh indikator penelitian yang diberikan dalam pernyataan kuesioner menunjukkan nilai keseluruhan item data bermakna valid. Dengan menunjukkan bahwa nilai dari Cronbach's Alpha dari masing-masing variabel yang diukur diantaranya variabel kualitas produk bernilai $0.782>0.6$ yang bermakna data reliabel, sedangkan pada variabel Promosi menunjukkan nilai sebesar $0.870>0.6$ yang berarti bahwa data yang didapatkan bermakna reliable kemudian variabel layanan bernilai $0.834>0.60$ dan variabel keputusan pembelian dengan nilai $0.789>0.60$.

Pengujian data dengan mengukur tingkat validitas dan reliabilitasnya telah menunjukkan hal yang baik selanjutnya peneliti akan mengukur tingkat koefisien korelasi atau nilai dari R square dari data yang telah diolah dengan menggunakan aplikasi SPSS.20.

Pengujian ini untuk mengetahui lemah kuatnya hubungan yang diberikan dari variabel kualitas produk, promosi, layanan terhadap keputusan pembelian. Dimana data yang telah running didapatkan hasilnya terlihat pada tabel 3 di atas. Data di atas menunjukkan bahwa besaran nilai dari $\mathrm{R}$ square adalah 0.626 atau sebesar $62.6 \%$ yang bermakna kuat, dimana kualitas produk, promosi dan layanan mampu memberikan hubungan yang kuat terhadap keputusan pembelian, sedangkan untuk nilai adjuste $R$ square sebesar 0.615 atau $61.5 \%$ yang bermakna bahwa jika terjadi perubahan dari nilai $\mathrm{R}$ square, maka nilai adjuste $R$ square yang menunjukkan keakuratan hubungan, dimana keakuratan hubungan dari kualitas produk, promosi dan layanan $\mathrm{t}$ terhadap keputusan pembelian sebesar $61.5 \%$ dan sisanya merupakan faktor lain yang tidak diteliti pada penelitian ini.

Pada tabel 4, menunjukkan data hasil output data regresi dimana didapatkan hasil dari turunan persamaan di atas, kemudian peneliti menjelaskan, bahwa nilai konstan sebesar 6.546 memiliki makna jika variabel kualitas produk,promosi dan layanan 0 maka nilai konsistensinya sebesar 6.546, sedangkan koefisien regresi dari kualitas produk,promosi dan layanan sebesar 0.615 yang bermakna bahwa jika terjadi perubahan 1 poin dari kualitas produk 
kesehatan, maka kepuasan pasien meningkat sebesar 0.615 atau sebesar $61.5 \%$ yang berarti nilai bermakna positif.

Pengukuran signifikansi dari penelitian ini berdasarkan pada pengukuran dasar dengan menggunakan nilai 0.05 , yang mana jika taraf signifikansi $0.05<$ dari hasil maka bermakna signifikan, sebaliknya jika nilai taraf signifikansi $0.05>$ nilai hasil hitung maka tidak signifikan. Dari hasil penelitian yang ditunjukkan pada tabel 4. di atas nilai probabilita atau taraf signifikansi yang didapatkan dalam penelitian ini sebesar 0.000 atau dengan kata lain $0.000<0.05$, yang bermakna bahwa kualitas produk,promosi dan layanan berpengaruh positif dan signifikan terhadap keputusan pembelian pada restoran Fast Food Wendy's Solobaru.

Hasil estimasi variabel kualitas produk diperoleh t hitung $=2.097$ dengan signifikansi sebesar $0,045<0,05$. Nilai signifikansi yang kurang dari 0,05 menunjukkan bahwa hipotesis yang menyatakan bahwa kualitas produk berpengaruh positif signifikan terhadap keputusan pembelian diterima. Dengan demikian Kualitas Produk mempunyai pengaruh yang signifikan terhadap keputusan konsumen. Hal ini dikarenakan pelanggan suka cita rasa yang diinginkan, berbagai varian burger yang enak, puas dengan harga yang terjangkau.

Hasil estimasi variabel promosi diperoleh $\mathrm{t}$ hitung $=2.674$, dengan signifikansi sebesar $0,012>0,05$. Nilai signifikansi yang lebih dari 0,05 menunjukkan bahwa hipotesis yang menyatakan bahwa promosi berpengaruh positif signifikan terhadap keputusan pembelian diterima. Dengan demikian Promosi mempunyai pengaruh yang signifikan terhadap keputusan konsumen. Hal ini dikarenakan pelanggan tertarik adanya promosi yang ada dimedia sosial, tertarik banner yang terpasang jelas, penjelasan informasi syarat dan ketentuan promosi lewat kartu Kredit maupun Debit yang dilakukan oleh karyawan untuk mendapatkan diskon up to 50\% menggunakan kartu tertentu.

Hasil estimasi layanan diperoleh t hitung $=2,525$, dengan signifikansi sebesar 0,017 > 0,05 . Nilai signifikansi yang lebih dari 0,05 menunjukkan bahwa hipotesis yang menyatakan bahwa layanan berpengaruh positif signifikan terhadap keputusan pembelian ditolak. Dengan demikian Pelayanan mempunyai pengaruh yang signifikan terhadap keputusan konsumen. Hal ini dikarenakan pelanggan merasa nyaman makan, pelayanan yang cepat, pembayaran tidak harus cash sudah ada mesin EDC yang akan mempermudah bertransaksi dengan adanya fasilitas modern.

\section{SIMPULAN DAN SARAN}

Berdasarkan hasil penelitian yang telah diuraikan sebelumnya, maka kesimpulan dalam penelitian ini adalah, kualitas produk promosi dan layanan secara simultan berpengaruh positif dan signifikan terhadap keputusan pembelian demikian juga pada uji partial dimana kualitas produk, promosi dan layanan berpengaruh positif dan signifikan secara tidak langsung terhadap keputusan pembelian.

Berdasarkan kesimpulan, maka disarankan pada restaurant Fast Food Wendy's Solobaru harus mampu mempertahankan kualitas produk, promosi dan layanan. Bagi peneliti selanjutnya hendaknya mengembangkan model penelitian dengan menambahkan variabel lain seperti variabel kepuasan dan loyalitas pelanggan.

\section{DAFTAR RUJUKAN}

Agustin, C.I. (2017). Pengaruh Kualitas Produk, Kualitas Pelayanan, dan Brand Image Terhadap Loyalitas Pelanggan Koran Jawa Pos Radar Kediri. Simki Economic, 2(3).

Irawan, Deny dan Japrianto Edwin, 2013. Analisa pengaruh kualitas produk terhadap loyalitas melalui kepuasan sebagai variabel intervening pada pelanggan restoran por kee surabaya.Jurnal Manajemen Pemasaran, VOL. 1, No. 2, (2013)1-8. Universitas Kristen Petra.

Kotler, Philip and Gary Armstrong. 2012. Prinsip-prinsip Pemasaran. Edisi 13. Jilid 1. Jakarta: Erlangga.

Kotler, Philip Dan Kevin Lane Keller. 2012. Marketing Management 14thed. New Jersey: Pearson Education.

Kristianto, Paulus Lilik, (2011). . Penerbit CAPS, Yogyakarta

Muhammad Amir, (2018). Pengaruh bauran pemasaran terhadap kepuasan konsumen perumahan pada PT. Cahaya fadillah utama di jeneponto. Bongaya Journal for Research in Management, Vol 1 No 1

Mustafa, Badollah.(2012) Promosi Jasa Perpustakaan. Tangerang Selatan, Universitas Terbuka

Sunyoto.D 2012. Manajemen Sumber Daya Manusia. Jakarta: PT Buku Seru 
M Tafsir, R Shaari, H Muchtar, F Firmansya, (2018). -The Effects of Product Quality and Interpersonal Communication on Customer Loyalty International Journal on Advanced Science, Education, Vol 1. 